\title{
Therapeutic effectiveness of percutaneous drainage and factors for performing an interval appendectomy in pediatric appendiceal abscess
}

Chih-Cheng Luo ${ }^{1,6^{*}+}$, Kuang-Fu Cheng ${ }^{5 \dagger}$, Chen-Sheng Huang ${ }^{1}$, Hung-Chieh Lo ${ }^{2}$, Sheng-Mao Wu ${ }^{2}$, Hung-Chang Huang ${ }^{3}$, Wen-Kuei Chien ${ }^{5}$ and Ray-Jade Chen ${ }^{4,6^{*}}$

\begin{abstract}
Background: In this study, we studied the therapeutic effectiveness of percutaneous drainage with antibiotics and the need for an interval appendectomy for treating appendiceal abscess in children with a research-oriented dataset released by the Bureau of National Health Insurance in Taiwan through the Collaboration Center for Health Information Application (CCHIA).

Methods: We identified 1225 patients under 18 years of age who had non-surgical treatment for an appendiceal abscess between 2007 and 2012 in a Taiwan CCHIA dataset. The treatment included percutaneous drainage with antibiotics or antibiotics alone. We also analyzed data of patient's baseline characteristics, outcomes of percutaneous drainage, and indicating factors for performing an interval appendectomy.

Results: Totally, 6190 children had an appendiceal abscess, an 1225 patients received non-operative treatment. Of 1225 patients, 150 patients received treatment with percutaneous drainage and antibiotics, 78 had recurrent appendicitis, 185 went on to receive an interval appendectomy, and 10 had postoperative complications after the interval appendectomy. We found that patients treated with percutaneous drainage and antibiotics had a significantly lower rate of recurrent appendicitis $(p<0.05)$, a significantly smaller chance of receiving an interval appendectomy $(p<0.05)$, and significantly fewer postoperative complications after the interval appendectomy $(p<$ $0.05)$ than those without percutaneous drainage treatment. Older children (13 18 years) patients were found to have a significantly smaller need to receive an interval appendectomy than those who were $\leq 6$ years of age (odd ratio $(\mathrm{OR})=2.071,95 \%$ confidence interval $(\mathrm{Cl})=1.34-3.19, p<0.01)$, and those who were $7 \sim 12$ years old (OR $=1$. $662,95 \% \mathrm{Cl}=1.15-2.41, p<0.01)$. In addition, those treated with percutaneous drainage were significantly less indicated to receive an interval appendectomy later $(\mathrm{OR}=2.249,95 \% \mathrm{Cl}=1.19 \sim 4.26, p<0.05)$. In addition, those with recurrent appendicitis had a significantly increased incidence of receiving an interval appendectomy later $(\mathrm{OR}=3.231,95 \% \mathrm{Cl}=1.95 \sim 5.35, p<0.001)$.

(Continued on next page)
\end{abstract}

\footnotetext{
*Correspondence: 102145@w.tmu.edu.tw; rayjchen@tmu.edu.tw

${ }^{\dagger}$ Equal contributors

${ }^{1}$ Division of Pediatric Surgery, Department of Surgery, Wan Fang Medical Center, Taipei Medical University, 111 Xinglong Rd., Sect. 3, 11696 Taipei, Taiwan

${ }^{4}$ Department of Surgery, Taipei Medical University Hospital, Taipei Medical University, 252 Wu-Xing Street, Taipei 110, Taiwan

Full list of author information is available at the end of the article
} 
(Continued from previous page)

Conclusions: In this study, we used nationwide data to demonstrate therapeutic effectiveness of percutaneous drainage and antibiotics was more beneficial than only antibiotics in treating patients with an appendiceal abscess. We also found three factors that were significantly associated with receiving an interval appendectomy: recurrent appendicitis, being aged $\leq 13$ years, and treatment with antibiotics only.

Keywords: Appendiceal abscess, Percutaneous drainage, Interval appendectomy

\section{Background}

Appendicitis is a common pediatric surgical emergency. Even with the use of ultrasonagraphy and computed tomography $(\mathrm{CT})$, perforation rates in children have been reported to be $30 \%$ over the last 30 years, and some perforated patients presented themselves with an appendiceal abscess [1-3].

Appendiceal abscess can immediately be treated by surgery or by non-surgical management, consisting of treatment with parenteral antibiotics alone, or treatment with antibiotics and ultrasound- or CT-guided drainage, followed by an interval appendectomy $[4,5]$. But the need for a future interval appendectomy remains debatable [610]. Without an interval appendectomy, the risks of recurrent appendicitis and missed pathological findings are uncertain. The recurrence rate after treatment with percutaneous drainage and antibiotics for patients with an appendiceal abscess was found to be low, and an interval appendectomy in most cases was not required $[11,12]$.

In this study, we used dataset from Taiwan's National Health Insurance (NHI) to analyze the effectiveness of percutaneous drainage therapy, and to determine the possible indicating factors for performing an interval appendectomy.

\section{Methods}

\section{Data source}

This study used data from the Taiwan National Health Insurance (NHI) program, which the government initiated in 1995, and which covers $99 \%$ of the population of 23 million people. The Bureau of the NHI (BNHI) in Taiwan has released a research-oriented database through the Collaboration Center for Health Information Application (CCHIA). In 1999, the BNHI began to release all claims data in electronic form, to allow researchers to trace almost all uses of medical services for all people in Taiwan, including all children with appendicitis.

We extracted datasets between 2007 and 2012 from the NHI research database (NHIRD) released by the BNHI through the CCHIA. The study protocol was approved by the Taipei Medical University Joint Institutional Review Board without the need to obtain signatures of study participants, because the NHIRD consists of de-linked secondary data.

\section{Study sample}

We enrolled 1225 pediatric patients ( $\leq 18$ years of age) with a diagnosis of an appendiceal abscess who received non-surgical treatment between January 2007 and December 2012, because the International Classification of Disease, Ninth Revision, Clinical Modification (ICD-9CM) codes were available since 2007.

Inpatient claims, which included records of all hospitalizations, provided a substantial amount of information. We linked study participants to the inpatient claims data to identify appendiceal abscess (540.9), percutaneous drainage $(470.22 \mathrm{C})$ and postoperative complications include an intra-abdominal abscess (IAA,998.59) and postoperative bowel obstruction (PBO,560.81 or 997.4) based on ICD-9-CM codes.

Patients were divided into three age groups: $\leq 6,7 \sim 12$, and $13 \sim 18$ years old. The definition of an interval appendectomy is a patient who had initial medical therapy with intravenous antibiotics or possibly drainage followed by an elective appendectomy. The definition of recurrent appendicitis is a patient who has appendicitis again after initial non-surgical treatment without an appendectomy. Excluded from the study were patients for whom the initial non-surgical treatment failed or who had recurrent appendicitis and received immediate surgery.

\section{Statistical analysis}

We performed a univariate analysis between different age group and treatment methods. We present continuous variables as the mean \pm standard deviation (SD) and analyzed differences in these parametric variables between groups with Student's $t$-test. We also present categorical variables as ratios, and analyzed differences in non-parametric variables between groups with Chisquare test. A multivariate logistic regression analysis was used to identify independent factors including factors of different age groups, gender, the use of antibiotics, the use of percutaneous drainage, and recurrent or non-recurrent appendicitis. The relationship between potential variables and the necessity for an interval appendectomy was assessed by odds ratios (ORs) and related $95 \%$ confidence intervals (CIs).

We used the Statistical Analytic System software version 9.3 (SAS Institute, Cary, NC, USA) to analyze the 
data in this study. Differences between groups were considered significant if $p$ values were $<0.05$.

\section{Results}

Totally, 6190 children had an appendiceal abscess, and non-surgical treatment was used in 1,225 patients. Table 1 lists of demographic data of all patients with an appendiceal abscess. Of 1225 patients, 185 received an interval appendectomy, 78 had recurrent appendicitis, and 10 had postoperative complications after an interval appendectomy.

Of the 1225 children presenting with an appendiceal abscess had non-surgical treatment. 150 (2.2 \%) patients were treated by percutaneous drainage with antibiotics, and the remaining 1075 (97.8\%) were only given antibiotics without percutaneous drainage. The average time of hospital stay for patients treated with percutaneous drainage (at $12.8 \pm 8.9$ days) was longer than that without drainage $(9.7 \pm 6.4$ days $)(p<0.05)$. Table 2 demonstrates that patients treated with percutaneous drainage and antibiotics had significantly lower rates of recurrent appendicitis $(p<0.05)$, a significantly smaller chance of receiving an interval appendectomy $(p<0.05)$, and a significantly smaller chance of postoperative complications $(p<0.05)$ after an interval appendectomy than those without percutaneous drainage treatment.

In our study (Table 1), 185 (15.1\%) patients received an interval appendectomy and the remaining 1040 $(84.9 \%)$ did not. Data from the multivariate logistic regression analyses (Table 3) showed that pediatric patients who received percutaneous drainage had a significantly smaller need to receive an interval appendectomy $(\mathrm{OR}=2.249,95 \% \mathrm{CI}=1.187 \sim 4.260, p<0.05)$, older (13 18 years) patients had a significantly smaller need to receive an interval appendectomy than those who were $\leq 6$ years, $(\mathrm{OR}=2.071,95 \% \mathrm{CI}=1.34 \sim 3.19$, $p<0.01$ ), and those who were $7-12$ years old ( $\mathrm{OR}=$ $1.662,95 \% \mathrm{CI}=1.15 \sim 2.41, p<0.01$ ), and patients with recurrent appendicitis were significantly likely to have an
Table 2 Comparison of therapeutic effectiveness in patients with and without percutaneous drainage

\begin{tabular}{lll}
\hline & Without drainage (\%) & With drainage (\%) \\
\hline $\begin{array}{lll}\text { R ecurrence } \\
\text { Yes }\end{array}$ & $73(6.79)$ & $5(3.33)^{\mathrm{a}}$ \\
No & $1002(93.21)$ & $145(96.67)$ \\
Interval appendectomy (IA) & $11(7.33)^{\mathrm{a}}$ \\
Yes & $174(16.19)$ & $139(92.67)$ \\
No & $901(83.81)$ & \\
Postoperative complications after IA & $0(0)^{a}$ \\
Yes & $10(5.75)$ & $11(100)$ \\
No & $164(94.25)$ &
\end{tabular}

${ }^{\text {a }}$ Significantly greater therapeutic effectiveness in patients with drainage compared with those without drainage $(p<0.05)$

increased incidence of receiving an interval appendectomy $(\mathrm{OR}=3.231,95 \% \mathrm{CI}=1.95 \sim 5.35, p<0.001)$.

\section{Discussion}

To the best of our knowledge, this is the first study to use a large nationwide database to study the effectiveness of percutaneous drainage therapy, and to determine the indicating factors for receiving an interval appendectomy in patients with appendiceal abscess.

Some recent reports mentioned that treatment of acute appendicitis with abscess formation or phlegmon with non-surgical management in children followed by an elective appendectomy has become well-recognized and accepted [13-15]. Non-surgical treatment of a pediatric appendiceal abscess is now also an acceptable approach in Taiwan. As shown in Table 1, $19.8 \%$ of patients with appendiceal abscess received non-surgical treatment, consisting of parenteral antibiotics alone and ultrasound- or CT-guided drainage, followed by an interval appendectomy $[4,5]$. We found that $12.2 \%$ of patients received treatment with percutaneous drainage and antibiotics, but another $87.8 \%$ of them received only antibiotics. Older children (13 18 years of age)

Table 1 Demographic data of appendiceal abscess patients

\begin{tabular}{|c|c|c|c|c|c|}
\hline Variable & $\begin{array}{l}\text { Patients with } \\
\text { aappendiceal } \\
\text { abscess }\end{array}$ & $\begin{array}{l}\text { Non-operative treatment } \\
n(\%)\end{array}$ & $\begin{array}{l}\text { Drainage } \\
n(\%)\end{array}$ & $\begin{array}{l}\text { Recurrence } \\
n(\%)\end{array}$ & $\begin{array}{l}\text { Interval appendectomy } \\
n(\%)\end{array}$ \\
\hline \multicolumn{6}{|c|}{ Age group (years) } \\
\hline$\leq 6$ & 628 & $233(37.1)$ & $27(11.6)$ & $18(7.8)$ & $47(20.2)$ \\
\hline $7 \sim 12$ & 2296 & $494(21.5)$ & $55(11.1)$ & $29(5.8)$ & $84(17.0)$ \\
\hline $13 \sim 18$ & 3266 & $498(15.2)$ & $68(13.7)$ & $31(6.2)$ & $54(10.8)$ \\
\hline \multicolumn{6}{|l|}{ Gender } \\
\hline Male & 3786 & $687(18.15)$ & $90(13.1)$ & $42(6.1)$ & $98(14.3)$ \\
\hline Female & 2404 & $538(22.38)$ & $60(11.2)$ & $36(6.6)$ & $87(16.1)$ \\
\hline Total & 6190 & $1225(19.8)$ & $150\left(12.2^{a}\right)$ & $78\left(6.3^{\mathrm{a}}\right)$ & $185\left(15.1^{a}\right)$ \\
\hline
\end{tabular}

a Percentage who received non-operative treatment 
Table 3 Multivariate logistic regression of indicating factors for performing an interval appendectomy

\begin{tabular}{lll}
\hline Variable & Odds ratio & $95 \%$ Confidence interval \\
\hline Gender & & \\
Female & 1 & - \\
Male & 1.025 & $0.743-1.414$ \\
Age group (years) & \\
$13-18$ & 1 & - \\
$7-12^{* *}$ & 1.662 & $1.146-2.410$ \\
$\leq 6^{* *}$ & 2.071 & $1.344-3.193$ \\
Drainage & & \\
Yes & 1 & - \\
No* & 2.249 & $1.187-4.260$ \\
Recurrence & & - \\
No & 1 & $1.950-5.354$ \\
Yes ${ }^{* * *}$ & 3.231 &
\end{tabular}

had an increased incidence of receiving percutaneous drainage in our study. In our opinion, the reason may have been that the technique of drainage is more easily to be performed in older children who are physically larger.

Previous reports revealed that percutaneous drainage with the use of antibiotics is more efficient than treatment with antibiotics alone to successfully and completely treat appendiceal abscess without an interval appendectomy $[11,12]$. We had the same findings (Table 2), showing that patients treated with percutaneous drainage and antibiotics had a significantly not only decreased rate of receiving an interval appendectomy $(p<0.05)$, but also had a significantly lower rate of recurrent appendicitis $(p<0.05)$ and had a significantly smaller chance of having postoperative complications $(p<0.05)$ after an interval appendectomy. The average time of hospital stay (12.8 \pm 8.9 days) was longer for patients treated with percutaneous drainage than those without drainage $(9.7 \pm 6.4$ days $)$ but with antibiotics alone $(p<0.05)$. Based on these data, we suggest that the therapeutic effectiveness of percutaneous drainage may be due to patients' hospitalization until drainage was completely stopped.

There are few reports dealing with indicating factors for performing an interval appendectomy. The presence of an appendicolith, increased blood C-reactive protein levels, elevated percent bands of white blood cells, and partial small bowel obstruction on admission are reported to be associated with an increased risk of recurrent appendicitis, and thus, such patients should receive an interval appendectomy [16-18]. In the multivariate logistic regression analyses from our national database (Table 3), we found that pediatric patients had a significantly smaller need to receive an interval appendectomy later on if they had received percutaneous drainage (OR $=2.249, p<0.05)$ and were significantly older (13 18 years $)(p<0.01)$. But if the pediatric patients had recurrent appendicitis, they had a significantly greater need to receive an interval appendectomy $(\mathrm{OR}=3.231$, $p<0.001)$.

\section{Study limitations}

Readers are warned against over-interpreting our study data because it has two major limitations. First, with a population-based database, we had no other available clinical data including patients' descriptions of clinical presentation, laboratory data, severity of appendiceal abscess, or pathologic confirmation of an appendiceal abscess. Second, we were unsure whether the staff surgeon decided to treat patients with non-surgical treatment, the use of percutaneous drainage, and performing an interval appendectomy.

\section{Conclusions}

In this our study, we used nationwide data in Taiwan to demonstrate that the therapeutic effectiveness of percutaneous drainage and antibiotics was more beneficial than antibiotics alone in treating patients with appendiceal abscess. We also found three factors significantly associated with receiving an interval appendectomy: recurrent appendicitis, being aged less than 13 years, and treatment with antibiotics only.

\section{Abbreviations}

BNHI: Bureau of NHI; CCHIA: Collaboration Center for Health Information Application; NHI: National Health Insurance

\section{Acknowledgements}

Winston W. Shen gave constructive editing comments on the manuscript.

\section{Funding}

No funding was obtained for this study.

\section{Availability of data and materials}

The data that support the findings of this data are available from [the Collaboration Center for Health Information Application (CCHIA)] but restrictions apply to the availability of these data, which were used under license which you must apply previously and be accepted for the current study, so are not publicly available. Data are however available from the authors upon reasonable request and with permission of [CCHIA].

\section{Authors' contributions}

L-CC (first author and correspond author) : contributed to conception and design the research, and had been involved in drafting the manuscript. C-KF (co-first author) : did analysis and interpretation of data, and was involved in drafting the manuscript. H-CS: investigated and resolved the questions related to the accuracy of the data within manuscript. L-HC : also help investigate and resolve the questions related to the accuracy of the data within manuscript. S-MW: was involved in drafting the manuscript. H-HC: revised important intellectual content of the manuscript. C-WK : had most acquisition of data, and analysis and interpretation of data. C-RJ (co-correspond author) : contributed to conception and design of the research and gave final approval of the version to be published. All authors read and approved the final manuscript.

Competing interests

The authors declare that they have no competing interests. 


\section{Consent for publication}

"Not applicable" in this section.

\section{Ethics approval and consent to the participate}

The study was approved by the TMU-Joint Institutional Review Board without the need of obtaining signature of study participants, reference number is 201404074.

\section{Author details}

'Division of Pediatric Surgery, Department of Surgery, Wan Fang Medical Center, Taipei Medical University, 111 Xinglong Rd., Sect. 3, 11696 Taipei, Taiwan. ${ }^{2}$ Department of Traumatology, Wan Fang Medical Center, Taipei Medical University, Taipei, Taiwan. ${ }^{3}$ Department of Acute Care Surgery and Traumatology, Taipei Medical University, Taipei, Taiwan. ${ }^{4}$ Department of Surgery, Taipei Medical University Hospital, Taipei Medical University, 252 Wu-Xing Street, Taipei 110, Taiwan. ${ }^{5}$ Biostatistics Center, Taipei Medical University, Taipei, Taiwan. ${ }^{6}$ Division of Pediatric Surgery, Department of Surgery, School of Medicine, College of Medicine, Taipei Medical University, No.250, Wuxing St, Taipei 11031, Taiwan.

Received: 4 March 2016 Accepted: 12 October 2016

Published online: 18 October 2016

\section{References}

1. Nance ML, Adamson WT, Hedrick HL. Appendicitis in the young child: a continuing diagnostic challenge. Pediatr Emerg Care. 2000;16:60-2.

2. Wagner JM, Mckinney WP, Carpenter JL. Does this patient have appendicitis? JAMA. 1996;276:1589-94.

3. Korner $\mathrm{H}$, Sondenaa $\mathrm{K}$, Soreide JA. Incidence of acute non-perforated and perforated appendicitis: Age-specific and sex-specific analysis. World J Surg. 1997;21:313-7.

4. Brown CV, Abrishami M, Muller M, Velmahos GC. Appendiceal abscess: immediate operation or percutaneous drainage? Am Surg. 2003;69:829-32.

5. Lidar Z, Kuriansky J, Rosin D, Shabtai M, Ayalon A. Laparoscopic interval appendectomy for periappendicular abscess. Laparoscopic interval appendectomy for periappendicular abscess. Surg Endosc. 2000;14:764-6.

6. Gillick J, Velayudham M, Puri P. Conservative management of appendix mass in children. Br J Surg. 2001:88:1539-42

7. Lai HW, Loong CC, Chiu JH, Chau GY, Wu CW, Lui WY. Interval appendectomy after conservative treatment of an appendiceal mass. World J Surg. 2006;30:351-7.

8. Ahmed I, Deakin D, Parsons S. Appendix mass: do we know how to treat it? Ann R Coll Surg Engl. 2005;87:191-5.

9. Gillick J, Mohanan N, Das L, Puri P. Laparoscopic appendectomy after conservative management of appendix mass. Pediatr Surg Int. 2008;24:299-301.

10. Puapong D, Lee SL, Haigh Pl, Kaminski A, Liu In-Lu A, Applebaum H. Routine interval appendectomy in children is not indicated. J Pediatr Surg. 2007;42:1500-3.

11. Zerem E, Salkic N, Imamovic G, Terzic I. Comparison of therapeutic effectiveness of percutaneous drainage with antibiotics versus antibiotics alone in the treatment of periappendiceal abscess. Laparoscopic interval appendectomy for periappendicular abscess. Surg Endosc. 2007;21:461-6.

12. Jonathan PR, David AP, Jennifer LB, Michael JA, Frederick MK, Moritz MZ. Complicated appendicitis in children: a clear role for drainage and delayed appendectomy. Am J Surg. 2007;194:769-73.

13. Vane DW, Fermandez $\mathrm{N}$. Role of interval appendectomy in the management of complicated appendicitis in children. World J Surg. 2006;30:51-4.

14. David FC, Wajid BJ, Jo M, Paul DL. Interval appendectomy in children clinical outcomes, financial costs and patient benefits. Pediatr Surg Int. 2014;30: 743-6.

15. Hall NJ, Jones CE, Eaton S, Stanton MP, Burge DM. Is interval appendectomy justified after successful nonoperative treatment of an appendix mass in children? a systematic review. J Pediatr Surg. 2011;46:767-71.

16. Ein SH, Langer JC, Daneman A. Nonoperative management of pediatric ruptured appendix with inflammatory mass or abscess: presence of an appendicolith predicts recurrent appendicitis. J Pediatr Surg. 2005;40:1612-5
17. Kogut KA, Blakely ML, Schropp KP, Deselle W, Hixson SD, Davidoff AM, et al. The association of elevated percent bands on admission and complications of interval appendectomy. J Pediatr Surg. 2001;36:165-8.

18. Tsai HM, Shan YS, Lin PW, Lin XZ, Chen CY. Clinical analysis of the predictive factors for recurrent appendicitis after initial nonoperative treatment of perforated appendicitis. Am J Surg. 2006;192:311-6.

\section{Submit your next manuscript to BioMed Central and we will help you at every step:}

- We accept pre-submission inquiries

- Our selector tool helps you to find the most relevant journal

- We provide round the clock customer support

- Convenient online submission

- Thorough peer review

- Inclusion in PubMed and all major indexing services

- Maximum visibility for your research

Submit your manuscript at www.biomedcentral.com/submit
C Biomed Central 